\section{OPEN ACCESS}

Edited by: Antonio Galvano, University of Palermo, Italy

Reviewed by:

Azin Nahvijou,

Tehran University of Medical

Science, Iran

Yan Du,

Fudan University, China

*Correspondence:

Hamid Salehiniya alesaleh70@yahoo.com

Specialty section:

This article was submitted to

Cancer Epidemiology and Prevention,

a section of the journal

Frontiers in Oncology

Received: 02 March 2021 Accepted: 14 April 2021

Published: 17 May 2021

Citation:

Alkatout I, Bieb/ M, Momenimovahed $Z$, Giovannucci E, Hadavandsiri F, Salehiniya H and Allahqoli L (2021) Has COVID-19 Affected Cancer Screening

Programs? A Systematic Review.

Front. Oncol. 11:675038.

doi: 10.3389/fonc. 2021.675038

\title{
Has COVID-19 Affected Cancer Screening Programs? A Systematic Review
}

\author{
Ibrahim Alkatout ${ }^{1}$, Matthias Biebl ${ }^{2}$, Zohre Momenimovahed ${ }^{3}$, Edward Giovannucci ${ }^{4,5}$, \\ Fatemeh Hadavandsiri ${ }^{6}$, Hamid Salehiniya ${ }^{7 *}$ and Leila Allahqoli ${ }^{8}$
}

${ }^{1}$ Kiel School of Gynaecological Endoscopy, University Hospitals Schleswig-Holstein, Kiel, Germany, ${ }^{2}$ Department of Surgery, Charité-Universitätsmedizin Berlin, Berlin, Germany, ${ }^{3}$ Department of Midwifery and Reproductive Health, Faculty of Nursing and Midwifery, Qom University of Medical Sciences, Qom, Iran, ${ }^{4}$ Departments of Nutrition and Epidemiology, Harvard T. H. Chan School of Public Health, Boston, MA, United States, ${ }^{5}$ Channing Division of Network Medicine, Department of Medicine, Brigham and Women's Hospital and Harvard Medical School, Boston, MA, United States, ${ }^{6}$ Cancer Research Center, Shahid Beheshti University of Medical Sciences, Tehran, Iran, ${ }^{7}$ Social Determinants of Health Research Center, Birjand University of Medical Sciences, Birjand, Iran, ${ }^{8}$ School of Public Health, Iran University of Medical Sciences (IUMS), Tehran, Iran

Background: Health care services across the world have been enormously affected by the onset of the coronavirus disease 2019 (COVID-19). Services in oncology have been curtailed because medical services have been focused on preventing the spread of the virus and maximizing the number of available hospital beds. The present study was designed to investigate the impact of COVID-19 on cancer screening.

Methods: Databases such as Medline, Web of Science Core Collection (Indexes = SClEXPANDED, SSCI, A \& HCl Timespan) and Scopus were searched comprehensively for articles published until January 2021. The keywords used were COVID-19 and cancer screening, Articles dealing with cancer screening in the COVID-19 pandemic were included in the review.

Results: The review comprised 17 publications. The impact of COVID-19 was categorized into four dimensions: a significant decline in cancer screening and pathology samples, the cancer diagnosis rate, an increase in advanced cancers, mortality rate and years of life lost (YLLs).

Conclusion: Cancer screening programs have been clearly interrupted since the onset of the COVID-19 disease. The anticipated outcomes include delayed diagnosis and marked increases in the numbers of avoidable cancer deaths. Urgent policy interventions are needed to handle the backlog of routine diagnostic services and minimize the harmful effects of the COVID-19 pandemic on cancer patients.

Keywords: cancer, screening, coronavirus disease 2019 (COVID-19), health care, diagnosis 


\section{BACKGROUND}

Coronavirus disease 2019 (COVID-19), also known as severe acute respiratory syndrome coronavirus 2 (SARS-CoV-2), which began in December 2019, has now reached every corner of the world (1). COVID-19 has affected 221 countries. More than 100 million cases of the disease were registered until 27 January 2021, which makes it the worst pandemic in modern history (2). Health care services across the globe have been profoundly affected by COVID-19, and the consequences of the pandemic are yet unforeseeable $(3,4)$. A large number of medical procedures, elective and non-urgent scheduled surgeries, and elective visits have been canceled or rescheduled $(5,6)$. Telehealth is used for non-acute issues in some countries (7), while population-based cancer screening programs have been suspended in others (5). The COVID 19 pandemic has had unprecedented effects on cancer screening and preventive care (8).

The enforcement of stay-at-home guidelines for reducing the risk of transmission (9) has influenced primary, secondary and tertiary preventive programs (7). Individuals with potential nonspecific symptoms of cancer have faced obstacles in consulting a specialist (7), largely due to fear and anxiety about being infected by COVID-19 in a health care setting. Both, patients and personnel at hospital sites experience fear and anxiety (5). There has been a marked decline in cancer screening and diagnosis, the development of tumor markers, the use of imaging procedures, biopsies, colonoscopy, gastroscopy, sigmoidoscopy, stool tests, low-dose computed tomography (LDCT), mammography, Pap tests, human papillomavirus (HPV) testing, colposcopy, laparoscopy, and melanoma screening $(6,8,10-22)$.

Cancers are known to develop long after exposure to carcinogens, such as tobacco or the human papillomavirus (HPV) (23) Thus, the carcinogenic process provides ample opportunity to detect early precancerous lesions and start interventions that reverse or delay the progression of disease (24). Delaying the initial quest for symptoms results in subsequent disease (7) and its irreversible consequences (17, $25,26)$. Any interruption of secondary preventive programs delays the diagnosis and treatment of cancer in addition to facilitating advanced disease, increasing mortality rates and total years of life lost (YLLs) (8, 16, 17, 25-28).

The suspension of cancer screening and early detection was deemed necessary in the initial phase of the COVID-19 pandemic, as demonstrated by a marked interruption in cancer screening rates during this time. COVID-19 could not be controlled within the initially anticipated period of time. As a result, routine cancer screening and treatment have not yet returned to pre-pandemic levels.

We have a limited body of data concerning the impact of COVID-19 on cancer screening programs. The impact of the pandemic on oncology is unpredictable because of changes in the behavior of the virus and lack of knowledge about the disease. In the present comprehensive systematic review, we reviewed published reports to determine the impact of COVID-19 on cancer screening programs. Papers on cancer screening published during the pandemic were reviewed in regard of cancer diagnosis and its impact on mortality rates and YLLs. We provide recommendations for future actions that will mitigate the potential negative effects of anti-COVID-19 measures on cancer screening. Strategies to handle similar events on a global basis are also addressed.

\section{METHODS}

\section{Search Strategy and Information Sources}

This systematic review was conducted in accordance with the systematic review checklist (PRISMA). The three databases PubMed/MEDLINE, Scopus, and Web of Science were searched for relevant articles. The search was performed on December 28, 2020 using the following keywords: "Early Detection," "Cancer," "Cancer Screening," "Cancer Screening Tests," "Early Diagnosis," "COVID 19," "Coronavirus Disease-19," "Coronavirus Disease," "SARS-CoV-2 Infection," "SARS-CoV-2," "2019-nCoV," "Coronavirus, 2019 Novel," "SARS CoV 2 Virus," "Severe Acute Respiratory Syndrome Coronavirus 2," "COVID-19," "Coronavirus Disease 19," "SARS Coronavirus 2". Boolean (AND, OR) operators and the MeSH terms were used to optimize the selection of records.

\section{Inclusion and Exclusion Criteria}

All types of observational studies conducted throughout the world, published exclusively in the English language, addressing cancer screening and diagnosis, cancer care, detection programs for early and appropriate detection and treatment were included in the review. Studies that did not address the specific effects of the coronavirus on cancer screening, included patients diagnosed with cancer prior to the pandemic, or patients with the symptomatic diagnosis of primary cancer, were excluded. Reviews, case reports, letters to editors, commentaries, and reports were also omitted. Studies were selected first by title and then by abstract. Their eligibility was then confirmed by a review of the full text. The PRISMA flow chart illustrates the process of selection.

\section{Screening of Studies and Study Selection}

After removing duplicates, the studies were first selected according to the relevance of their titles and abstract (LA and HS). Next, full-text articles were reviewed to confirm eligibility (LA and IA). Articles that addressed any single aspect of cancer screening during the COVID-19 pandemic period were included. All retrieved articles were entered into a database on Endnote X7.

\section{Data Extraction and Data Items}

We used a pre-prepared checklist for data extraction, the following information was extracted from each study: the first author's last name, country, study design (source of the data), type of cancer and screening, study objectives, main findings, and recommendation. 


\section{Quality Assessment}

To assess the quality of articles included in the review, the Newcastle-Ottawa Quality Assessment Form was used. This tool contains of 3 separate sections: selection, comparison, and result. Studies scored based on the overall scores and divided into 3 categories: Good, Fair and Poor (29).

\section{RESULTS}

\section{Selection of Studies}

The various databases yielded a total of 828 publications, of which 273 were duplicate articles. Of the remaining 555, 510 were omitted after reviewing the title and abstract. Seven of the remaining 45 articles were omitted for the following reasons: two were non-English publications and five were letters to the editor, review or commentaries. After a review of full texts, a further 22 articles were omitted because the contents were not aligned to the objectives. Finally, 16 studies were included in a systematic review (Figure 1).

\section{Study Characteristics}

Seventeen studies deemed eligible for the investigation were divided into the following four categories: cancer screening and pathology samples $(3,8,14,16,17,27,28,30-33)$, cancer diagnosis in the COVID-19 period and factors related to the reduced diagnosis of cancer $(8,17,26,27,31,34,35)$, impact of lockdown-related delay of medical care on tumor stage at the time of diagnosis $(17,25,27,30,32-34,36-38)$, mortality rate and YLLs $(17,38)$. Based on our review using the relevant checklist, 15 studies had good quality and 1 article had moderate quality.

\section{Cancer Screening and Pathology Samples}

COVID-19 has interrupted cancer screening such that, during the pandemic, reduced rates of cancer were reported from all screening programs $(3,8,14,16,17,27,28,30-33)$. The effect was more pronounced in countries with a greater prevalence of COVID-19 or poorly controlled rates of COVID-19 infection. Compared to the pre-COVID period, colonoscopy rates fell by $4.1 \%$ to $75 \%(8,28)$. Gastroscopies, prostate, and lung screening rates were reduced by $57 \%, 74 \%$, and $56 \%$, respectively $(28,30)$. Screening mammograms declined by $22.2-85 \%(3,16,28,32)$. We attribute this difference to the prevalence of COVID-19 in various countries.

Cancer screening rates have dropped at all levels of hospital care and in nearly all age groups (38).

Furthermore, the histopathological investigation of cancer screening-related samples has been severely affected by COVID-19. The histopathological and cytological workload was reduced by $35-72 \%$ compared to the preceding three years (14). Reductions in cancer biopsies were reported for breast $(-31$ to $-71 \%)$, colon $(-33$ to $-79 \%)$, and lung cancer $(-47$ to $-58 \%)$ (28). In Belgium, de Pelsemaeker and registered a significant drop in the number of breast resection specimens and pulmonary endobronchial ultrasound (EBUS) biopsies (14).
The impact of COVID-19 on cancer screening and pathology samples is summarized in Table $\mathbf{1}$.

\section{Cancer Diagnosis in the COVID-19 Period and Factors Related to the Reduced Diagnosis of Cancer}

One of the consequences of reduced cancer screenings is a decline in cancer diagnosis rates $(8,17,26,27,31,34,35)$. According to De Vincentiis et al., cancer diagnosis at the Pathologic Anatomy Unit serving a Secondary Care Hospital Network in the Province of Macerata, Italy during the COVID pandemic fell by $11 \%$ compared to the average numbers in the last few years (39\% vs 50\%). However, various reduction rates were noted for the different types of cancer (34) (Table 2). A study in the Netherlands reported a steep decline in the absolute number of "suspicious of gastrointestinal (GI) cancers" and "colon cancers" (31). In Canada, a three- and sixmonth interruption in the breast screening program caused a $7 \%$ and $14 \%$ drop in cancer diagnosis (17). A marked drop in newly diagnosed gynecological tumors (-24\% to $-49 \%)$ was reported in Austria during the COVID-19 pandemic, and the median age of the patients was significantly lower than that of patients diagnosed with cancer in 2019 (59.4 vs. 61.3 years). A nearly 10\% decline was noted in the diagnosis of breast cancer (35). The impact of COVID-19 on cancer diagnosis is summarized in Table 2.

Fear of being infected by COVID-19 on the part of patients (8), halted screening programs in hospitals, the re-deployment of staff towards critical care for the management of patients with COVID-19, and changing strategies in hospitals for the prevention of nosocomial infection (27) were reasons for fewer cancers being diagnosed during the COVID-19 pandemic.

\section{Impact of Lockdown-Related Delay of Medical Care on Tumor Stage at the Time of Diagnosis}

The interruption of cancer prevention due to suspended cancer screenings may delay the diagnosis $(17,25,33,34,36,37)$, increase the numbers of symptomatic patients (27), and disclose cancers in more advanced stages (36). In an investigation of 3184 patients, Ricciardiello et al. concluded that a delay of 7-12 and > 12 months would lead to a significant $3 \%$ and $7 \%$ increase in the detection of advanced cancers (25) (Figure 2).

A study in Canada showed that three- and six-month interruptions in breast and colorectal cancer screening would lead to more numerous cases being detected in a late stage (stage IIIA or worse) between 2020 and 2029. Besides, longer interruptions (12 months) would have a greater impact on the spike in advanced cancers (17). The impact of lockdown-related delays in medical care on tumor stage at the time of diagnosis is summarized in Table 3.

According to predictions, once the lockdown has been lifted it will take a minimum of 12-24 weeks to clear the queue of missed cancer screenings $(32,38)$. Lang and coworkers reported that, after resuming screening, a mere $68 \%$ of the Lung Cancer Screening (LCS) reached the average weekly pre-COVID volume in the following 10 weeks (30). According to Maringe et al., even after all restrictions on cancer screening have been lifted, it will take 3-6 months for screening figures to return to pre-pandemic levels (38). 

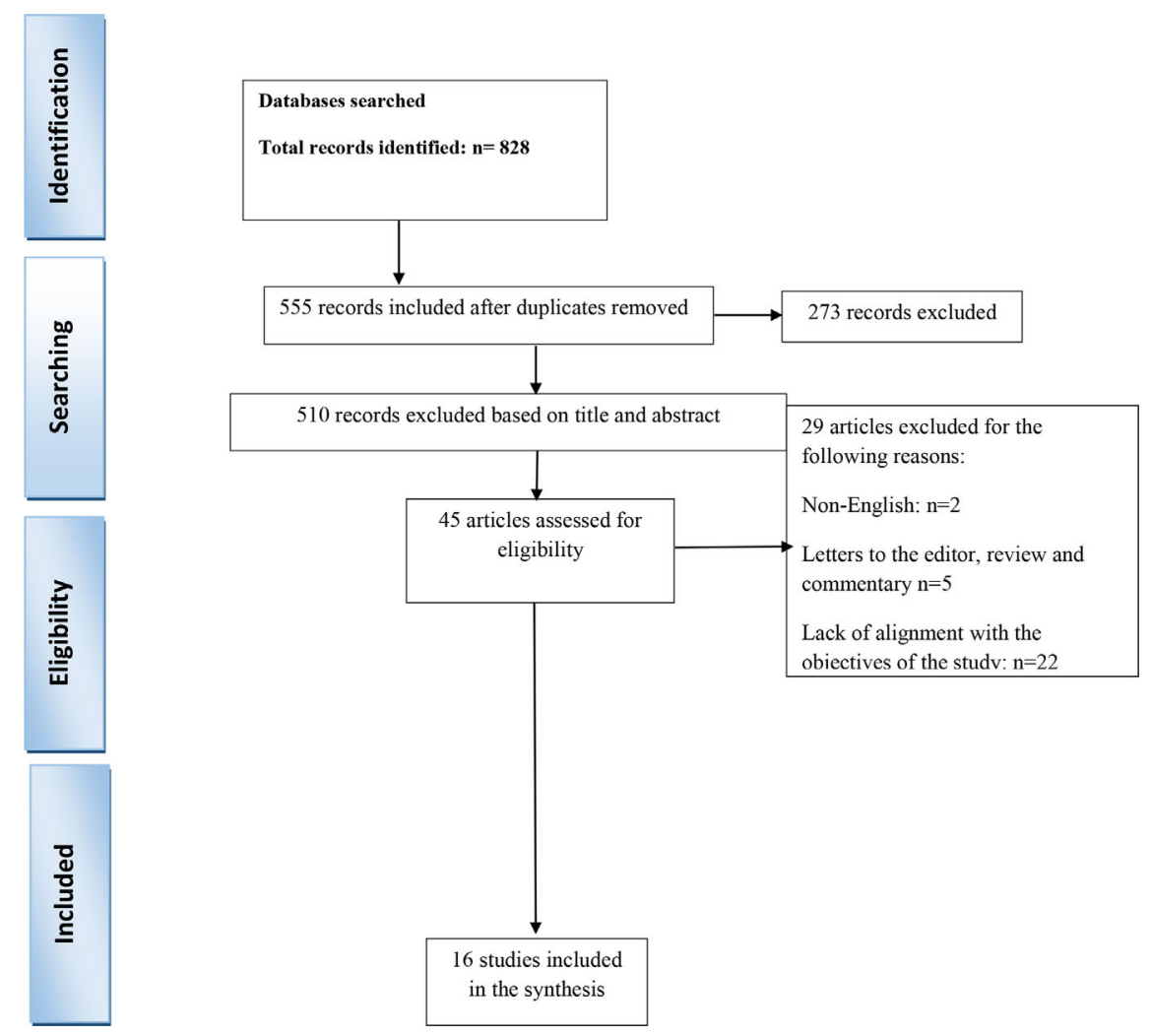

FIGURE 1 | Study flow diagram.

\section{Mortality Rate and YLLs}

The effect of delayed cancer diagnosis will not be perceived in the immediate future alone; premature deaths may occur as long as five years later $(17,38)$. According to a study performed in Canada, cumulative excess deaths following the interruption of cancer services will continue to rise well beyond 2029 (17).

In a study conducted in England, death rates were compared with pre-pandemic figures. Increased death rates are anticipated up to five years after the diagnosis. Mortalities secondary to breast cancer (total number of breast cancer $n=32,583$ ) will increase annually from 965 (95\% CI 958-972) to 1028 (1019-1036). Annual deaths due to lung cancer (total number of lung cancer $\mathrm{n}=29,305)$ are estimated to increase from 18,443 (95\% CI 18,388$18,503)$ to $19,855(19,804-19,901)$. Deaths due to colorectal cancer (total number of colorectal cancer $n=24,975$ ) will increase annually from 5051 (95\% CI 5004-5099) to 6078 (6032-6140). Corresponding figures for esophageal cancer $(n=6744)$ will be 3656 (95\% CI 3642-3670) to 4034 (4017-4050) (38).

The estimated cumulative numbers of cancer deaths in the UK up to year 5 after the diagnosis are shown in Figure 3A. This figure was extrapolated from the total number of cancer deaths in the UK (total breast cancer deaths $\mathrm{n}=11,839$; colorectal cancer deaths $\mathrm{n}=21,107$, lung cancer deaths $\mathrm{n}=36,518$; and esophageal cancer deaths $n=8450$ ) reported by the International Agency for Research on Cancer (IARC) (39). Maringe et al. anticipate 7.9-9.6\%, 15.3-
$16.6 \%, 4.8-5.3 \%$, and $5.8-6.0 \%$ increases in the numbers of deaths due to breast, colorectal, lung, and esophageal cancers, respectively, up to year 5 after the diagnosis (38).

Cancer deaths due to COVID-19 throughout the world were calculated on the basis of the cancer database IARC (39) and a published study (38). Delayed cancer screening is estimated to cause the following additional numbers of cancer deaths secondary to breast, esophageal, lung, and colorectal cancer, respectively: $54,112-65,756,31,556-32,644,86,214-95,195$, and 143,081-155,238 in the worldwide (Figure 3B).

Any interruption in cancer services without adequate strategies to accommodate individuals who missed their screening would lead to years of life lost. Maringe and coworkers determined the numbers of years of life lost due to additional deaths attributable to four cancer types (breast, lung, colorectal, and esophageal) at five years, and reported an anticipated 59,204 to 63,229 YLLs secondary to additional deaths (3291 to 3621) from the four cancer types during the first five years after diagnosis (38). Yong et al. estimated that a six-month interruption in breast and colorectal cancer screening would potentially result in 8000 (95\% CI 3500-12,000) years of life lost over the lifetime (17). These statistics clearly underline the fragility of established health care systems. Indeed, the COVID-19 pandemic could challenge the resilience of health programs in oncology. The major interruption of cancer services 
TABLE 1 | Impact of COVID-19 on cancer screening and pathology samples.

\begin{tabular}{|c|c|c|c|c|c|}
\hline First Author & Country & $\begin{array}{c}\text { Study Design/source of the } \\
\text { data }\end{array}$ & $\begin{array}{c}\text { Quality } \\
\text { Assessment }\end{array}$ & Screening type & Main result \\
\hline Cheng (8) & Taiwan & $\begin{array}{l}\text { Prospective observational } \\
\text { study (University Hospital } \\
\text { screening) }\end{array}$ & Good & $\begin{array}{l}\text { Colonoscopy } \\
\text { (fecal immunochemical test) }\end{array}$ & $\begin{array}{l}\text { Screening uptake rates were } 88.8 \% \text { between December } \\
2019 \text { and April 2020, and } 91.2-92.7 \% \text { in the preceding } \\
\text { three years. } \\
\text { The colonoscopy rate during the pandemic (66.1\%) was } \\
\text { significantly lower than that in the preceding three years } \\
(70.2-77.5 \%) \text {. } \\
\text { Up to } 10.9 \% \text { of screening investigations were rescheduled } \\
\text { or canceled, which was significantly higher than the } \\
\text { cancellations in the preceding three } 3 \text { years. A half of the } \\
\text { cancellations were due to fear of infection. }\end{array}$ \\
\hline De & Belgium & Prospective observational & Fair & Cancer screening & The histological and cytological workup of colon biopsies, \\
\hline $\begin{array}{l}\text { Pelsemaeker } \\
\text { (14) }\end{array}$ & & $\begin{array}{l}\text { study (Cliniques universitaires } \\
\text { Saint-Luc) }\end{array}$ & & $\begin{array}{l}\text { (histological and cytological } \\
\text { samples, } \\
\text { immunohistochemistry and } \\
\text { molecular tests) }\end{array}$ & $\begin{array}{l}\text { breast biopsies, and cervical cytology were reduced by } \\
\text { fear of COVID-19 infection. }\end{array}$ \\
\hline Mizuno (27) & Japan & $\begin{array}{l}\text { Retrospective cohort study } \\
\text { (tertiary emergency hospital) }\end{array}$ & Good & $\mathrm{CRC}$ & $\begin{array}{l}\text { A drop in ambulant colonoscopy rates and emergency } \\
\text { admissions at the start of the pandemic. }\end{array}$ \\
\hline Patt (28) & USA & $\begin{array}{l}\text { Retrospective analysis } \\
\text { (clearinghouse database } \\
\text { representing } 5 \%-7 \% \text { of the } \\
\text { Medicare fee-for-service } \\
\text { population) }\end{array}$ & Good & $\begin{array}{l}\text { Cancer care (breast, colon, } \\
\text { lung biopsy) }\end{array}$ & $\begin{array}{l}\text { Screenings for breast, colon, prostate, and lung cancers } \\
\text { were reduced by } 85 \%, 75 \%, 74 \% \text {, and } 56 \% \text {, respectively. } \\
\text { Reduced biopsy rates were also observed in April and July } \\
\text { for breast }(-71 \% \text { and }-31 \%) \text {, colon (-79\% and }-33 \%) \text {, } \\
\text { and lung }(-58 \% \text { and }-47 \%) \text { cancer } \\
\text { E\&M visits (-74\%), new patient E\&M visits (-70\%), and } \\
\text { established patient E\&M visits (-60\%) were significantly } \\
\text { reduced. }\end{array}$ \\
\hline Yin (16) & USA & $\begin{array}{l}\text { Retrospectively analysis ( } 55 \\
\text { breast imaging centers } \\
\text { from } 27 \text { states) }\end{array}$ & Good & $\begin{array}{l}\text { Breast surgery, breast } \\
\text { imaging }\end{array}$ & $\begin{array}{l}\text { Breast surgery }(20.5 \%) \text {, breast imaging }(61.7 \%) \text {, and } \\
\text { genetic consultations dropped to } 39.9 \% \text { of the average } \\
\text { weekly volumes before COVID- } 19 .\end{array}$ \\
\hline Yong (17) & Canada & $\begin{array}{l}\text { Simulation modeling analysis } \\
\text { (Canadian Cancer Registry) }\end{array}$ & Good & $\begin{array}{l}\text { Cancer screening (breast } \\
\text { and } \mathrm{CRC} \text { ) }\end{array}$ & $\begin{array}{l}\text { A three-month interruption of breast cancer screening due } \\
\text { to COVID-19 resulted in } 644,000 \text { fewer screens. }\end{array}$ \\
\hline
\end{tabular}

LDCT, Low-dose computed tomography (for lung cancer screening); LCS, Lung cancer screening; CRC, Colorectal cancer screening; E\&M, hospital out-patient evaluation and management.

may well be expected to neutralize achievements in the field for a whole decade. The estimated effects of COVID-19 on mortality rates and YLLs are summarized in Table 4.

\section{DISCUSSION}

COVID-19 is believed to have influenced cancer screening programs (7). The present systematic review was designed to investigate the impact of COVID-19 on cancer screening and suggest global measures to counteract future threats. The effect of the COVID-19 pandemic on cancer screening and diagnosis is expected to result in more numerous advanced cancers as well as increase cancer mortality rates and YLLs.

In the present study, all published studies by countries with different prevalence of COVID-19 have been reviewed. Based on the report WHO, COVID-19 in the United States, England, and Italy has been highly prevalent, whereas Taiwan had a lowly 
TABLE 2 | Impact of COVID-19 on cancer diagnosis.

\begin{tabular}{|c|c|c|c|c|c|}
\hline $\begin{array}{l}\text { First } \\
\text { Author }\end{array}$ & Country & $\begin{array}{l}\text { Study Design/ } \\
\text { source of the data }\end{array}$ & $\begin{array}{c}\text { Quality } \\
\text { Assessment }\end{array}$ & $\begin{array}{l}\text { Screening } \\
\text { type }\end{array}$ & Main result \\
\hline $\begin{array}{l}\text { De } \\
\text { Vincentiis } \\
\text { (34) }\end{array}$ & Italy & $\begin{array}{l}\text { Retrospectively } \\
\text { analysis (Hospital } \\
\text { based) }\end{array}$ & Good & $\begin{array}{l}\text { Cancer } \\
\text { diagnosis } \\
\text { (cellular } \\
\text { pathology) }\end{array}$ & $\begin{array}{l}\text { Cancers were diagnosed in 50\% during } 2018 \text { and } 2019 \text { compared to 39\% in } 2020 \text {. } \\
\text { Reductions were most notable for prostate }(75 \%) \text {, bladder }(66 \%) \text { and colorectal } \\
\text { cancers (62\%), moderate for breast cancer (26\%), slight for gastric cancer (10\%), } \\
\text { minimal for lung cancer (2\%), and no reductions were noted for metastatic and } \\
\text { pancreatic cancers, and skin melanoma. }\end{array}$ \\
\hline $\begin{array}{l}\text { Gathani } \\
(26)\end{array}$ & England & $\begin{array}{l}\text { Retrospectively } \\
\text { analysis (National } \\
\text { database) }\end{array}$ & Good & $\begin{array}{l}\text { Breast cancer } \\
\text { diagnoses }\end{array}$ & $\begin{array}{l}\text { Breast cancer diagnosis in the first half of } 2020 \text { was } 28 \% \text { lower than that during the } \\
\text { same period in } 2019 .\end{array}$ \\
\hline $\begin{array}{l}\text { Lantinga } \\
\text { (31) }\end{array}$ & Netherlands & $\begin{array}{l}\text { Retrospectively } \\
\text { analysis (database } \\
\text { registry from } 20 \\
\text { Dutch hospitals) }\end{array}$ & Good & $\begin{array}{l}\text { Gastrointestinal } \\
\text { endoscopy }\end{array}$ & $\begin{array}{l}\text { Detection of cancer decreased by } 35.12 \% \text { (from } 524 \text { to } 340 \text { ); } \\
\text { the likelihood of detecting cancer during endoscopy increased } \\
(2.7 \% \text { [ } 95 \% \text { confidence interval (Cl) 2.5-3.0] in } 2019 \text { vs. 3.5\% [95\% Cl 3.1-3.9] in } \\
\text { 2020). }\end{array}$ \\
\hline $\begin{array}{l}\text { Mizuno } \\
(27)\end{array}$ & Japan & $\begin{array}{l}\text { Retrospective } \\
\text { cohort study(tertiary } \\
\text { emergency hospital) }\end{array}$ & Good & $\mathrm{CRC}$ & A drop in colorectal cancers detected by cancer screening. \\
\hline Yong (17) & Canada & $\begin{array}{l}\text { Simulation modeling } \\
\text { analysis } \\
\text { (Canadian Cancer } \\
\text { Registry) }\end{array}$ & Good & $\begin{array}{l}\text { Cancer } \\
\text { screening } \\
\text { (breast and } \\
\text { CRC) }\end{array}$ & $\begin{array}{l}\text { A three- and six-month interruption would cause a } 7 \% \text { (from } 28,500 \text { to } 26,600 \text { ) and } \\
14 \% \text { (from } 28,500 \text { to } 24,400 \text { ) drop in diagnoses, respectively. } \\
\text { This would be accompanied by an increase in non-screening-detected cancers of } \\
550 \text { and } 1020 \text { ( } 10 \% \text { and } 19 \% \text { increase) that year for three- and six-month } \\
\text { interruptions, respectively, with the increase persisting for at least a year after } \\
\text { screening resumes. } \\
\text { A six-month interruption in colorectal screening would cause the early diagnosis of } \\
19,000 \text { adenomas and colorectal cancers to be missed. }\end{array}$ \\
\hline
\end{tabular}

$\mathrm{Cl}$, Confidence interval; $\mathrm{CRC}$, Colorectal cancer screening.

prevalence (40). Published studies have disclosed a marked decline in cancer screening, diagnostic imaging, as well as histopathological and cytological biopsies during the COVID19 pandemic $(8,14,26,27,30,31,34,36,37,41)$. The reduction has been attributed to stay-at-home orders, patients' fear of infection, hesitation to seek care, the perceived risk of exposure to COVID-19 for clinicians, changing hospital policies in redeployment of staff towards critical care for the management of COVID-19 patients, triage of patients with COVID-19 infection, and the cessation of cancer screening in hospitals (28).
Short-term (3-6 months) and long-term (>12 months) interruption of cancer screening will delay the diagnosis of cancers and cause a shift in favor of more advanced cancers $(15,17,31,36,38,42)$. Cancer in advanced stages requires more complex care, is associated with a lower likelihood of response to therapy and cure of the disease, higher costs $(10,15,28,43)$, and graver outcomes (8). Despite limited evidence, Yin et al. showed that a short-term interruption (3-4 months) of cancer screening may not necessarily influence cancer stage. Evidently, the subject calls for further investigation (16).

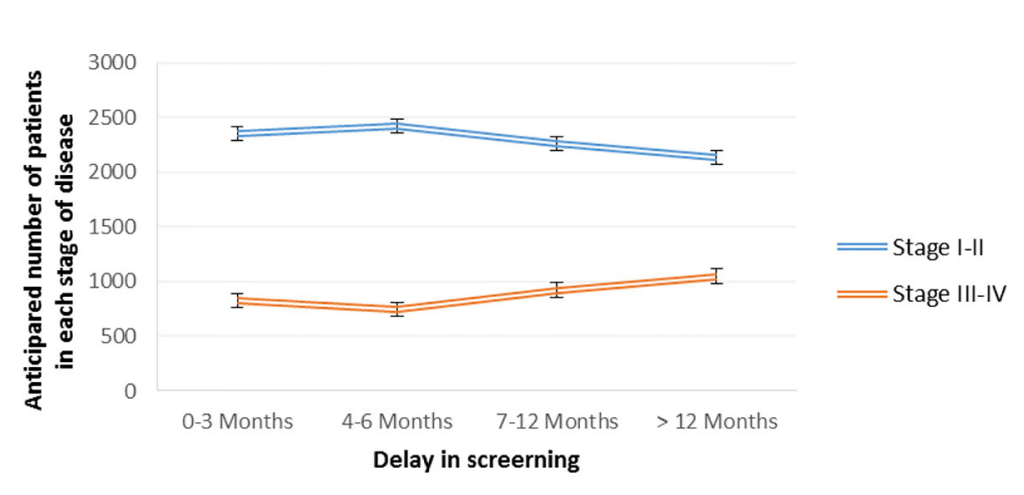

FIGURE 2 | Estimated colorectal cancer progression due to delayed diagnosis in various intervals, based on Ricciardiello et al. (25). 
TABLE 3 | Impact of lockdown-related delays in medical care on tumor stage at the time of diagnosis.

\begin{tabular}{|c|c|c|c|c|c|}
\hline $\begin{array}{l}\text { First } \\
\text { Author }\end{array}$ & Country & $\begin{array}{c}\text { Study Design/source } \\
\text { of the data }\end{array}$ & $\begin{array}{c}\text { Quality } \\
\text { Assessment }\end{array}$ & Screening type & Main result \\
\hline $\begin{array}{l}\text { D'Ovidio } \\
(37)\end{array}$ & Italy & $\begin{array}{l}\text { Retrospective } \\
\text { controlled cohort study } \\
\text { (Hospital base) }\end{array}$ & Good & CRC & $\begin{array}{l}\text { The "high-risk" adenomas detection rate was significantly higher in the "lockdown } \\
\text { group" than in controls ( } 47 \% \text { vs. } 25 \%) \text {. } \\
\text { Colorectal cancers were more numerous in the "lockdown group" than in controls } \\
\text { ( } 8 \% \text { vs. } 1 \%) \text {. } \\
\text { Multiple regression analysis showed that the lockdown period }(\mathrm{HR}, 2.2) \text { was an } \\
\text { independent predictor of high-risk adenomas and colorectal cancers }\end{array}$ \\
\hline $\begin{array}{l}\text { Van } \\
\text { Haren } \\
(33)\end{array}$ & USA & $\begin{array}{l}\text { Prospective } \\
\text { observational study } \\
\text { (institutional LDCT } \\
\text { screening database) }\end{array}$ & Good & LDCT screening & $\begin{array}{l}\text { Lung nodules suspicious for malignancy (Lung-RADS 4) after resumption of routine } \\
\text { surgery were increased by } 21 \% \text {. } \\
\text { Enlarged nodules after surgery were increased by } 31.3 \% \text {. }\end{array}$ \\
\hline $\begin{array}{l}\text { Yong } \\
(17)\end{array}$ & Canada & $\begin{array}{l}\text { Simulation modeling } \\
\text { analysis } \\
\text { (Canadian Cancer } \\
\text { Registry) }\end{array}$ & Good & $\begin{array}{l}\text { Cancer } \\
\text { screening, } \\
\text { (breast and } \\
\text { CRC) }\end{array}$ & $\begin{array}{l}\text { A three- and six-month service interruption would lead to } 310 \text { and } 670 \text { more cancers } \\
\text { detected in an advanced stage (stage IIIA or higher). } \\
\text { A 12-month interruption of breast cancer screening will be followed by } 62 \% \text { of } \\
\text { cancers in advanced stages. } \\
\text { A three-month or six-month screening interruption would lead to } 1100 \text { or } 2200 \text { more } \\
\text { colorectal cancers, respectively; and more than } 60 \% \text { of cases would be in an } \\
\text { advanced stage (III or IV). }\end{array}$ \\
\hline
\end{tabular}

CRC, Colorectal cancer screening; HR, hazard ratio; LCS LDCT, lung cancer screening low-dose computed tomography scan; Lung RADS, Lung CT Screening Reporting and Data System.

In a national, population-based modeling study in England, Maringe et al. reported that delays in cancer diagnosis would lead to excess short-term cancer mortality and 40,000 years of life lost (38).

On account of delays in cancer diagnosis in Canada, Yong et al. predicted approximately 5300 additional breast cancer deaths and 4500 additional deaths due to colorectal cancer (17). Sud et al. claimed that in England a delay of 3-6 months in cancer screening and surgery will exert a significant impact on survival and mitigate $19-43 \%$ of life-years gained (44).

The suspension of cancer screening or cancer prevention programs may be expected to aggravate the patients' suffering, disease burden, mortality rates at 5 years, the economic burden, and the workload for surgeons and oncologists $(36,38)$. Even after the resumption of routine diagnostic services, the current backlogs in medical and surgical subspecialties will cause substantial delays (38). On the other hand, a surge in diagnosed cancer diagnosis is expected when screening resumes (17).

Current projections indicate that the COVID-19-related disruption may last for 18 months or longer. The medical community and the world at large will be faced with significant challenges in the near future. Cancer screening programs must be implemented despite the lack of information for health care workers and patients concerning their risk of contracting COVID-19 from various health care interactions. Especially in the current setting, we need policies to promote access to cancer care, support the cancer care ecosystem, and minimize morbidity and mortality rates during and after the pandemic.

- Measures should be instituted at the health system level (national or jurisdictional) as well as the health service level (including specialist and primary care, in both the public and private sectors) to identify and address system-wide cancer control as well as support high-quality cancer care.
- Cancer screening services should be resumed early while respecting infection prevention (social distancing, using personal protective equipment [PPE], vaccination etc.). Prioritization of health care and reallocation of resources will be needed to minimize the negative impact of delayed diagnosis and therapy for oncological patients. Simultaneously, adequate numbers of health care workers should be assigned and suitable spaces provided for screening in order to ensure timely care for patients with alarm symptoms. A proportionate increase in funds earmarked for health care should also be taken into account.

- Raising diagnostic resources is complex because it requires effective coordination across all hospital subspecialties and not just in specialized cancer teams.

- Dividing institutions into Covid-dedicated hospitals and Covid-free institutions may be useful to reduce the risk and fear of infection among non-COVID patients. Hospital staff would require less protective equipment at Covid-free hospitals. The latter would also not experience any shortage of personnel for performing elective high-risk procedures.

- After a brief period of training, less specialized staff such as general practitioners (GP), midwives or nurses could be involved in screening programs. National cancer societies should establish guidelines and design a screening questionnaire for risk stratification. The screening questionnaires could include specific questions such as the number of first-degree relatives with cancer, whether a screening investigation (colonoscopy, mammography, etc.) was performed for non-screening purposes over the last 5-10 years, and with what results.

- Outreach services could be provided to enhance access to health services and improve overall retention at the national level. Outreach services would ensure the stability of cancer screening in a similar public health crisis. 


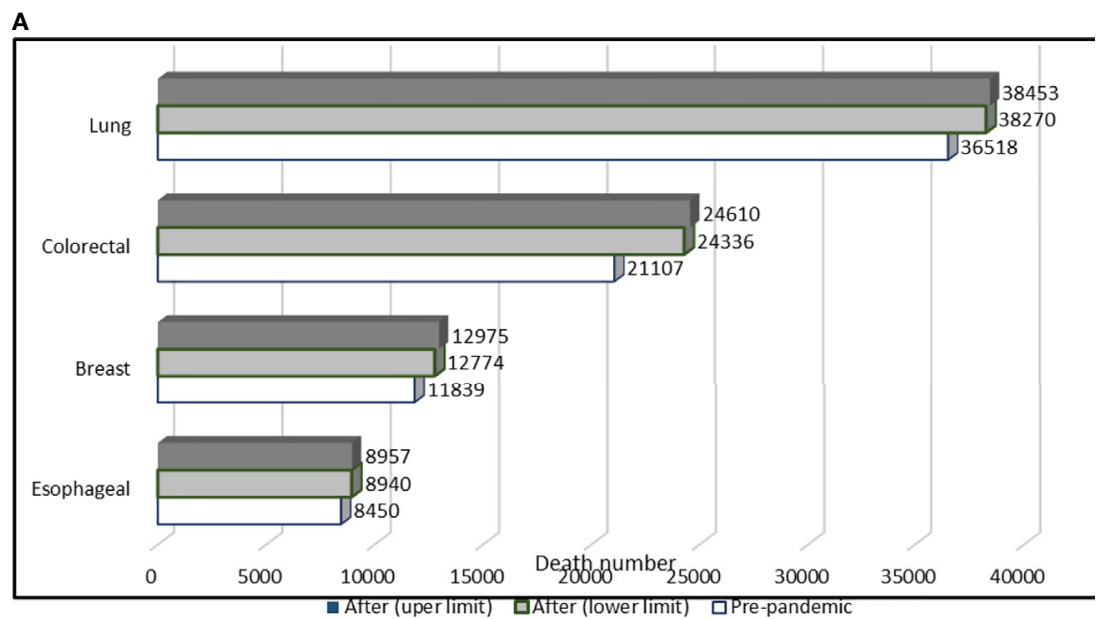

B

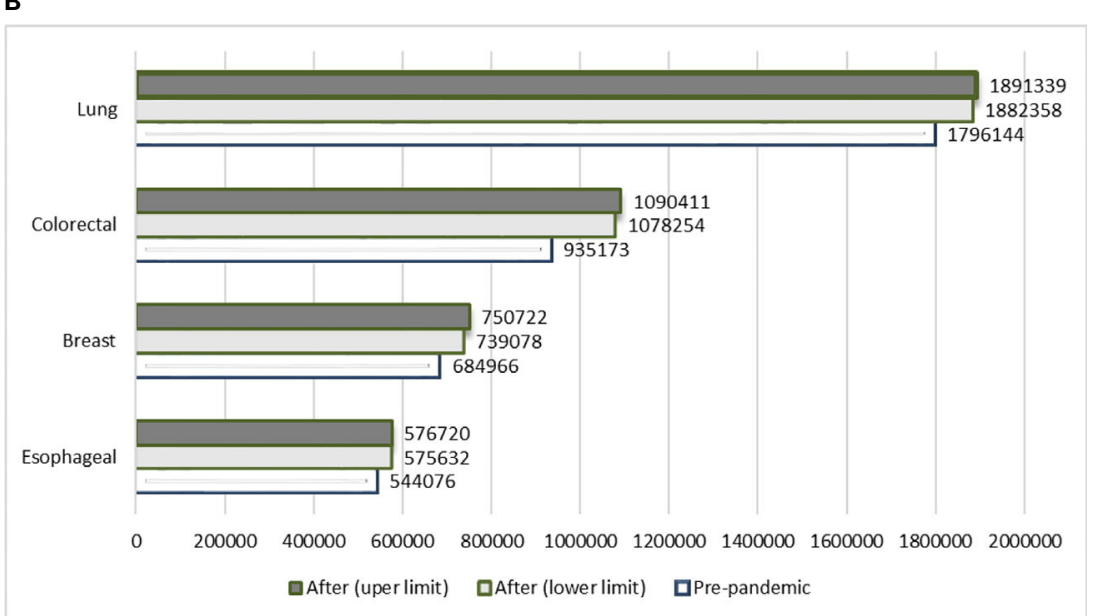

FIGURE 3 | (A) Estimated cumulative number of deaths in the UK due to breast, colorectal, lung, and esophageal cancers up to year 5 after the diagnosis. (B) Estimated cumulative numbers of deaths throughout the world due to breast, colorectal, lung, and esophageal cancer up to 5 years after the diagnosis (Calculated numbers are an estimate). Based on the data published by Maringe and coworkers, we anticipate a minimum 7.9-9.6\%, 15.3-16.6\%, 4.8-5.3\%, and 5.8-6.0\% increase in the numbers of deaths due to breast, colorectal, lung, and esophageal cancer, respectively, up to year 5 after the diagnosis (38, 39).

- Policy-makers would be well advised to consider the establishment of a flexible outreach system into the community as a preparation for future pandemics.

- Public health messaging should accurately convey the risk of severe illness due to COVID-19 versus the risk of not seeking healthcare advice if patients are symptomatic, and provide evidence-based information for clinicians to balance the risks for patients against the benefits of medical procedures during the pandemic.

- Cancer screening education apps via smartphones or tablet devices should be used to educate the population about cancer screening.

- Dedicated cancer awareness programs will need to consider a wide range of media channels in order to reach their target groups. A media-led education intervention could be used to enhance the awareness of the public and their attendance of screening tests.

- Cancer programs should encompass telemedicine and teleworking to ensure the continuum of care without losing clinical and human contact. Technology is increasingly used across the health care system to improve the quality and efficiency of care. Artificial intelligence (AI) has the potential to transform the delivery of cancer care. The pandemic warrants further development of artificial intelligence in medical research and its use in optimizing cancer care (45).

- Further measures include self-sampling, such as that employed for HPV testing, the use of rapid diagnostic kits (Fecal Immunochemical Test or FIT) and the return the samples by postal mail. Self-sampling is believed to be equivalent to clinician sampling and can be taught by simple graphics or animated video presentation.

The world is currently in a state of shock. Urgent policy interventions are needed to handle the backlog of routine diagnostic services and minimize the effect of the COVID-19 
TABLE 4 | Impact of COVID-19 on mortality rates and YLLs in cancer patients.

\begin{tabular}{|c|c|c|c|c|c|c|}
\hline $\begin{array}{l}\text { First } \\
\text { Author }\end{array}$ & Country & $\begin{array}{l}\text { Study Design/ } \\
\text { source of the data }\end{array}$ & $\begin{array}{c}\text { Quality } \\
\text { Assessment }\end{array}$ & $\begin{array}{l}\text { Cancer type or } \\
\text { screening } \\
\text { (sample size) }\end{array}$ & Additional death & $\begin{array}{l}\text { Decline in the } \\
\text { survival of } \\
\text { cancer patients } \\
\text { at } 5 \text { years after } \\
\text { diagnosis: }\end{array}$ \\
\hline \multirow[t]{4}{*}{$\begin{array}{l}\text { Maringe } \\
(38)\end{array}$} & England & $\begin{array}{l}\text { National population- } \\
\text { based Modelling } \\
\text { study (National }\end{array}$ & & $\begin{array}{l}\text { Total number of } \\
\text { cancer patients } \\
(93,607)\end{array}$ & $\begin{array}{l}\text { Additional deaths due to these four cancer types at } 5 \text { years after } \\
\text { diagnosis: } 3291 \text { and } 3621 \text {. }\end{array}$ & \\
\hline & & & & Lung $(29,305)$ & $\begin{array}{l}1235 \text { (1220-1254) to } 1372 \text { (1343-1401) additional deaths, a 4.8- } \\
5.3 \% \text { increase }\end{array}$ & $3.5 \%$ \\
\hline & & & & CRC $(24,975)$ & $\begin{array}{l}1445 \text { (1392-1591) to } 1563(1534-1592) \text { additional deaths, a 15.3- } \\
16.6 \% \text { increase }\end{array}$ & $6.4 \%$ \\
\hline & & & & $\begin{array}{l}\text { Esophageal } \\
(6,744)\end{array}$ & $\begin{array}{l}330(324-335) \text { to } 342(336-348) \text { additional deaths, a } 5.8-6.0 \% \\
\text { increase up to } 5 \text { years after diagnosis. }\end{array}$ & $6.1-6.3 \%$ \\
\hline $\begin{array}{l}\text { Yong } \\
(17)\end{array}$ & & & & $\mathrm{CRC}$ & $\begin{array}{l}\text { A six- and 12- month service interruption with immediate restoration } \\
\text { of screening would lead to } 450 \text { and } 930 \text { cumulative excess } \\
\text { colorectal cancer deaths, respectively, between } 2020 \text { and } 2029 \text {. } \\
\text { If a } 24 \text {-month transition period of reduced colorectal screening } \\
\text { volumes followed the interruption, the number of deaths for a six- } \\
\text { and } 12 \text {-month interruption would increase from } 450 \text { to } 1150 \text { and } \\
930 \text { to } 1800 \text { deaths, respectively. }\end{array}$ & \\
\hline
\end{tabular}

YLLs, Years of life lost; $n$, Number; CRC, Colorectal cancer.

pandemic on cancer patients. While the majority of published studies have been focused on the short-term (three- or sixmonth) effects of interrupted cancer screening, some countries had been involved with COVID-19 for more than a year. According to the WHO prediction, the second year of COVID-19 will be more difficult because of the emergence of new variants. Further negligence of cancer screening programs will intensify the crisis. Experts around the world should work together to develop a protocol that will minimize the consequences of this problem. When we return to our lifestyles prior to the COVID-19 crisis, we will be faced with the following question: to what extent have survival standards and our overall quality of life been affected by the change in cancer screening programs? Investigators all over the world will be faced with the task of collecting data in order to answer this critical question.

In summary, changes in cancer services due to international pandemic measures are expected to result in a large number of additional cancer deaths. A significant decline in cancer screening and biopsy sampling is expected that in the short term reduce cancer diagnosis rates and in the long term increase cancer diagnosis rates, advanced cancers, mortality rates and years of life lost (YLLs). The reason for these long-term sequelae can be traced to the unpreparedness of the world for such a catastrophe. Indeed, in the initial phases of the pandemic, it was estimated that the problem would be resolved in a few months and all delays would be compensated. However, the sheer duration of the pandemic affected health policies throughout the world.

\section{LIMITATIONS}

The use of English-language articles might have limited the results of this study. Crucial data published in other languages may have been omitted. The small sample size of some studies and the use of easy and accessible sampling may have impaired the generalizability of the studies. The strengths of the study may be summarized as follows: it is a comprehensive review of the impact of COVID-19 on all cancer screening programs, and provides practical suggestions for dealing with COVID-19 during and after the current pandemic.

\section{AUTHOR CONTRIBUTIONS}

All authors contributed in all sections and writing. All authors contributed to the article and approved the submitted version. 


\section{REFERENCES}

1. WHO. Coronavirus Disease (COVID-19): Situation Report. (2020). Available at: https://www.who.int/emergencies/diseases/novel-coronavirus-2019/situation-reports

2. WHO. Who Director-General's Opening Remarks At the Media Briefing on COVID-19 - 11 January 2021. (2020). Available at: https://www.who.int/ director-general/speeches/detail/who-director-general-s-opening-remarksat-the-media-briefing-on-covid-19-11-january-2021.

3. Tsai H-Y, Chang Y-L, Shen C-T, Chung W-S, Tsai H-J, Chen F-M. Effects of the COVID-19 Pandemic on Breast Cancer Screening in Taiwan. Breast (2020) 54:52-5. doi: 10.1016/j.breast.2020.08.014

4. Alkatout I, Karimi-Zarchi M, Allahqoli L. Gynecological Cancers and the Global COVID-19 Pandemic. J Turkish German Gynecol Assoc (2020) 21 (4):272-8. doi: 10.4274/jtgga.galenos.2020.2020.0119

5. Gong K, Xu Z, Cai Z, Chen Y, Wang Z. Internet Hospitals Help Prevent and Control the Epidemic of COVID-19 in China: Multicenter User Profiling Study. J Med Internet Res (2020) 22(4):e18908. doi: 10.2196/18908

6. Karimi-Zarchi M, Allahqoli L, Nehmati A, Kashi AM, Taghipour-Zahir S, Alkatout I. Can the Prophylactic Quadrivalent HPV Vaccine be Used as a Therapeutic Agent in Women With CIN? A Randomized Trial. BMC Public Health (2020) 20(1):274. doi: 10.1186/s12889-020-8371-z

7. Dinmohamed AG, Visser O, Verhoeven RHA, Louwman MWJ, van Nederveen FH, Willems SM, et al. Fewer Cancer Diagnoses During the COVID-19 Epidemic in the Netherlands. Lancet Oncol (2020) 21(6):750-1. doi: 10.1016/S1470-2045(20)30265-5

8. Cheng SY, Chen CF, He HC, Chang LC, Hsu WF, Wu MS, et al. Impact of COVID-19 Pandemic on Fecal Immunochemical Test Screening Uptake and Compliance to Diagnostic Colonoscopy. J Gastroenterol Hepatol (2020) 20:10.1111/jgh.15325. doi: 10.1111/jgh.15325

9. CDC. Coronavirus Disease 2019 (Covid-19) 2020. Available at: https://www. cdc.gov/coronavirus/2019-ncov/index.html.

10. Villani A, Fabbrocini G, Costa C, Scalvenzi M. Melanoma Screening Days During the Coronavirus Disease 2019 (COVID-19) Pandemic: Strategies to Adopt. Dermatol Ther (2020) 10:525-7. doi: 10.1007/s13555-020-00402-x

11. Ajenifuja KO, Belinson J, Goldstein A, Desai KT, de Sanjose S, Schiffman M. Designing Low-Cost, Accurate Cervical Screening Strategies That Take Into Account COVID-19: A Role for Self-Sampled HPV Typing. Infect Agents Cancer (2020) 15(1):61. doi: 10.1186/s13027-020-00325-4

12. He T, MacIsaac MB, Hume SJ, Thompson AJ, Schulberg JD. Covid-19 and its Impact on Endoscopy Services: What is the Threshold for Missed Malignant Diagnosis? Gut (2020) 26:gutjnl-2020-322769. doi: 10.1136/gutjnl-2020-322769

13. Momenimovahed Z, Salehiniya H. Delay in the Diagnosis of Breast Cancer During Coronavirus Pandemic. EXCLI J (2021) 20:142-4. doi: 10.17179/ excli2020-3318

14. de Pelsemaeker M-C, Guiot Y, Vanderveken J, Galant C, Van Bockstal MR. The Impact of the COVID-19 Pandemic and the Associated Belgian Governmental Measures on Cancer Screening, Surgical Pathology and Cytopathology. Pathobiology (2020) 87(4):1-10. doi: 10.1159/000509546

15. Vigliar E, Iaccarino A, Bruzzese D, Malapelle U, Bellevicine C, Troncone G. Cytology in the Time of Coronavirus Disease (covid-19): An Italian Perspective. J Clin Pathol (2020) 74(4):261-3. doi: 10.1136/jclinpath-2020-206614

16. Yin K, Singh P, Drohan B, Hughes KS. Breast Imaging, Breast Surgery, and Cancer Genetics in the Age of COVID-19. Cancer (2020) 126(20):4466-72. doi: $10.1002 / \mathrm{cncr} .33113$

17. Yong JH, Mainprize JG, Yaffe MJ, Ruan Y, Poirier AE, Coldman A, et al. The Impact of Episodic Screening Interruption: COVID-19 and Population-Based Cancer Screening in Canada. J Med Screen (2020) 26:0969141320974711. doi: $10.1177 / 0969141320974711$

18. Corso G, Gilardi L, Girardi A, De Scalzi AM, Pagani G, Rossi EMC, et al. How Useful are Tumor Markers in Detecting Metastases With FDG-PET/CT During Breast Cancer Surveillance? Oncology (2020) 98(10):714-8. doi: 10.1159/000507707

19. Kim J, Kim KH. Role of Chest Radiographs in Early Lung Cancer Detection. Trans Lung Cancer Res (2020) 9(3):522. doi: 10.21037/tlcr.2020.04.02

20. Wu J, Hu S, Zhang L, Xin J, Sun C, Wang L, et al. Tumor Circulome in the Liquid Biopsies for Cancer Diagnosis and Prognosis. Theranostics (2020) 10 (10):4544. doi: 10.7150/thno.40532
21. Palmerola R, Smith P, Elliot V, Reese CT, Mahon FB, Harpster LE, et al. The Digital Rectal Examination (DRE) Remains Important - Outcomes From a Contemporary Cohort of Men Undergoing an Initial 12-18 Core Prostate Needle Biopsy. Can J Urol (2012) 19(6):6542-7.

22. Li Z, Ji J. Application of Laparoscopy in the Diagnosis and Treatment of Gastric Cancer. Ann Trans Med (2015) 3(9):126. doi: 10.3978\%2Fj.issn.23055839.2015.03.29

23. Nadler DL, Zurbenko IG. Estimating Cancer Latency Times Using a Weibull Model. Adv Epidemiol (2014) 2014:746769. doi: 10.1155/2014/746769

24. Murphy S, Xu J, Kochanek K, Curtin S, Arias E. Deaths: Final Data for 2015 Vol. 66. Hyatsville, MD: National Vital Statistics Reports (2017).

25. Ricciardiello L, Ferrari C, Cameletti M, Gaiani F, Buttitta F, Bazzoli F, et al. Impact of SARS-CoV-2 Pandemic on Colorectal Cancer Screening Delay: Effect on Stage Shift and Increased Mortality. Clin Gastroenterol Hepatol (2020) 6:S1542-3565(20)31236-2. doi: 10.1016/j.cgh.2020.09.008

26. Gathani T, Clayton G, MacInnes E, Horgan K. The COVID-19 Pandemic and Impact on Breast Cancer Diagnoses: What Happened in England in the First Half of 2020. Br J Cancer (2021) 124(4):710-2. doi: 10.1038/s41416-020 01182-Z

27. Mizuno R, Ganeko R, Takeuchi G, Mimura K, Nakahara H, Hashimoto K, et al. The Number of Obstructive Colorectal Cancers in Japan has Increased During the COVID-19 Pandemic: A Retrospective Single-Center Cohort Study. Ann Med Surg (2020) 60:675-9. doi: 10.1016/j.amsu.2020.11.087

28. Patt D, Gordan L, Diaz M, Okon T, Grady L, Harmison M, et al. Impact of COVID-19 on Cancer Care: How the Pandemic is Delaying Cancer Diagnosis and Treatment for American Seniors. JCO Clin Cancer Inf (2020) 4:1059-71. doi: 10.1200/CCI.20.00134

29. Penson DF, Krishnaswami S, Jules A, Seroogy JC, McPheeters ML. Evaluation and Treatment of Cryptorchidism. United States: Rockville (MD): Agency for Healthcare Research and Quality (2012) Report No.: 13-EHC001-EF.

30. Lang M, Yeung T, Shepard JO, Sharma A, Petranovic M, Flores EJ, et al. Operational Challenges of a Low-Dose Ct Lung Cancer Screening Program During the Coronavirus Disease 2019 Pandemic. Chest (2020) 159(3):128891. doi: 10.1016/j.chest.2020.10.045

31. Lantinga MA, Theunissen F, Ter Borg PC, Bruno MJ, Ouwendijk RJ, Siersema PD. Impact of the COVID-19 Pandemic on Gastrointestinal Endoscopy in the Netherlands: Analysis of a Prospective Endoscopy Database. Endoscopy (2020) 53(2):166-70. doi: 10.1055/a-1272-3788

32. Song H, Bergman A, Chen AT, Ellis D, David G, Friedman AB, et al. Disruptions in Preventive Care: Mammograms During the COVID-19 Pandemic. Health Serv Res (2020) 56(1):95-101. doi: 10.1111/14756773.13596

33. Van Haren RM, Delman AM, Turner KM, Waits B, Hemingway M, Shah SA, et al. Impact of the COVID-19 Pandemic on Lung Cancer Screening Program and Subsequent Lung Cancer. J Am Coll Surgeons (2021) 232(4):600-5. doi: 10.1016/j.jamcollsurg.2020.12.002

34. De Vincentiis L, Carr RA, Mariani MP, Ferrara G. Cancer Diagnostic Rates During the 2020 'Lockdown', Due to COVID-19 Pandemic, Compared With the 2018-2019: An Audit Study From Cellular Pathology. J Clin Pathol (2021) 74:187-9. doi: 10.1136/jclinpath-2020-206833

35. Tsibulak I, Reiser E, Bogner G, Petru E, Hell-Teutsch J, Reinthaller A, et al. Decrease in Gynecological Cancer Diagnoses During the COVID-19 Pandemic: An Austrian Perspective. Int J Gynecol Cancer (2020) 30 (11):1667-71. doi: 10.1136/ijgc-2020-001975

36. Del Vecchio Blanco G, Calabrese E, Biancone L, Monteleone G, Paoluzi OA. The Impact of COVID-19 Pandemic in the Colorectal Cancer Prevention. Int J Colorectal Dis (2020) 35(10):1951-4. doi: 10.1007/s00384-020-03635-6

37. D’Ovidio V, Lucidi C, Bruno G, Lisi D, Miglioresi L, Bazuro ME. Impact of COVID-19 Pandemic on Colorectal Cancer Screening Program. Clin Colorectal Cancer (2020) 20(1):e5-e11. doi: 10.1016/j.clcc.2020.07.006

38. Maringe C, Spicer J, Morris M, Purushotham A, Nolte E, Sullivan R, et al. The Impact of the COVID-19 Pandemic on Cancer Deaths Due to Delays in Diagnosis in England, UK: A National, Population-Based, Modelling Study. Lancet Oncol (2020) 21(8):1023-34. doi: 10.1016/S1470-2045(20)30388-0

39. Data Visualization Tools for Exploring the Global Cancer Burden in 2020 [Internet]. WHO (2020). Available at: https://gco.iarc.fr/today/fact-sheetspopulations. 
40. Worldmeter. covid-19 Coronavirus Pandemic Worldometer 2021. Available at: https://www.worldometers.info/coronavirus/.

41. Alkatout I, Strack M, Maass N, Boos M, Hopf N. Ethical Decision-Making in the Face of Increasing Economization of Hospitals: A Study on Ethical Mistrust in Decisions Taken on the Length of Hospital Stay Among Students and Doctors. Wiener Medizinische Wochenschrift (1946) (2020) 170(13-14):367-75. doi: 10.1007/s10354-020-00742-5

42. Freer PE. The Impact of the COVID-19 Pandemic on Breast Imaging. Radiol Clinics North Am (2021) 59(1):1-11. doi: 10.1016/j.rcl.2020.09.008

43. Alkatout I. Communicative and Ethical Aspects of Physician-Patient Relationship in Extreme Situations. Wiener Medizinische Wochenschrift (1946) (2015) 165(23-24):491-8. doi: 10.1007/s10354-015-0385-2

44. Sud A, Jones M, Broggio J, Loveday C, Torr B, Garrett A, et al. Collateral Damage: The Impact on Outcomes From Cancer Surgery of the COVID-19 Pandemic. Ann Oncol (2020) 31(8):1065-74. doi: 10.1016/j.annonc. 2020.05.009
45. Moawad GN, Elkhalil J, Klebanoff JS, Rahman S, Habib N, Alkatout I. Augmented Realities, Artificial Intelligence, and Machine Learning: Clinical Implications and How Technology Is Shaping the Future of Medicine. J Clin Med (2020) 9(12):3811. doi: 10.3390/jcm9123811

Conflict of Interest: The authors declare that the research was conducted in the absence of any commercial or financial relationships that could be construed as a potential conflict of interest.

Copyright () 2021 Alkatout, Biebl, Momenimovahed, Giovannucci, Hadavandsiri, Salehiniya and Allahqoli. This is an open-access article distributed under the terms of the Creative Commons Attribution License (CC BY). The use, distribution or reproduction in other forums is permitted, provided the original author(s) and the copyright owner(s) are credited and that the original publication in this journal is cited, in accordance with accepted academic practice. No use, distribution or reproduction is permitted which does not comply with these terms. 